\title{
Skin Diseases in Family Medicine: Prevalence and Health Care Use
}

\author{
Elisabeth W. M. Verboeven, MSc ${ }^{1}$ \\ Floor W. Kraaimaat, $\mathrm{PbD}^{1}$ \\ Chris van Weel, $\mathrm{PbD}^{2}$ \\ Peter C. M. van de Kerkbof, $\mathrm{PbD}^{3}$ \\ Piet Duller, MSc ${ }^{1,3}$ \\ Pieter G. M. van der Valk, PbD \\ Henk J. M. van den Hoogen ${ }^{2}$ \\ J. Hans J. Bor ${ }^{2}$ \\ Henk J. Schers, PbD ${ }^{2}$ \\ Andrea W. M. Evers, $P b D^{1,3}$ \\ 'Department of Medical Psychology, Rad- \\ boud University Nijmegen Medical Centre, \\ Nijmegen, the Netherlands \\ ${ }^{2}$ Department of Family Practice, Radboud \\ University Nijmegen Medical Centre, \\ Nijmegen, the Netherlands \\ ${ }^{3}$ Department of Dermatology, Radboud \\ University Nijmegen Medical Centre, \\ Nijmegen, the Netherlands
}

Conflicts of interest: none reported

\section{CORRESPONDING AUTHOR}

Andrea W. M. Evers, PhD

Department of Medical Psychology (840)

Radboud University Nijmegen

Medical Centre

PO Box 9101, 6500 HB Nijmegen

The Netherlands

a.evers@mps.umcn.nl

\begin{abstract}
PURPOSE Ongoing care for patients with skin diseases can be optimized by understanding the incidence and population prevalence of various skin diseases and the patient-related factors related to the use of primary, specialty, and alternative health care for these conditions. We examined the recent prevalence of skin diseases in a defined population of family medicine patients, self-reported disease-related quality of life, extent and duration of skin disease, and the use of health care by patients with skin diseases.
\end{abstract}

METHODS We undertook a morbidity registry-based epidemiological study to determine the prevalence of various skin diseases, using a patient questionnaire to inquire about health care use, within a network of family practices in the Netherlands with a practice population of approximately 12,000 citizens.

RESULTS Skin diseases accounted for $12.4 \%$ of all diseases seen by the participating family physicians. Of the 857 questionnaires sent to patients registered with a skin disease, 583 (68.0\%) were returned, and 501 were suitable for analysis. In the previous year, $83.4 \%$ of the patients had contacted their family physician for their skin disease, $17.0 \%$ had contacted a medical specialist, and $5.2 \%$ had consulted an alternative health care practitioner. Overall, $65.1 \%$ contacted only their family physician. Patients who reported more severe disease and lower quality of life made more use of all forms of health care.

CONCLUSION This practice population-based study found that skin diseases account for $12.4 \%$ of diseases seen by family physicians, and that some skin problems may be seen more frequently. Although patients with more extensive skin diseases also obtain care from dermatologists, most patients have their skin diseases treated mainly by their family physician. Overall, patients with more severe disease and a lower quality of life seek more treatment.

Ann Fam Med 2008;6:349-354. DOI: 10.1370/afm.861.

\section{INTRODUCTION}

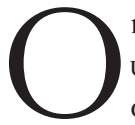

ngoing care for people with skin diseases can be optimized by understanding the incidence and population prevalence of various skin diseases and the patient-related factors (eg, disease severity, psychosocial well-being) related to the use of primary, specialty, and alternative health care for these conditions. Although skin diseases are common among the general population and account for a high percentage of all diseases dealt with by family physicians, ${ }^{1-8}$ recent prevalence data are desirable considering the reported increase in the prevalence of specific skin diseases (eg, atopic dermatitis and carcinoma of the skin). ${ }^{9-11}$ Additionally, the use of health care by patients with skin diseases has rarely been investigated. ${ }^{1,2,12}$

The goal of this study was to examine the prevalence of skin diseases, the use of health care by patients with skin diseases, and the relationship between this use of health care and disease-related variables (eg, disease severity and quality of life). We expected more patients with more severe skin diseases and a lower skin-related quality of life to seek more treatment. 


\section{METHODS}

\section{The Continuous Morbidity Registration}

This research was conducted within the Continuous Morbidity Registration (CMR) of the Department of Family Practice, Radboud University Nijmegen Medical Centre, the Netherlands. ${ }^{13-16}$ The CMR was founded in 1971 and consists of 4 family practices and 11 family physicians. It records all new episodes of diseases encountered by family physicians participating in the network. As a diagnosis-based disease registry, CMR records diagnoses according to the adapted E-list, ${ }^{17,18}$ which is compatible with the International Classification of Health Problems in Primary Care (ICHPPC-2).${ }^{19}$ In the Netherlands each person is registered with 1 family physician, who is a gatekeeper to access to specialist medical care. This system enables the CMR to register referrals to medical specialists, as well as the specialist-reported diagnoses. The CMR network covers a relatively stable practice population of approximately 12,000 citizens, which is representative in terms of age and sex of the Dutch general population. All patients were informed about the use of the database and asked to provide written consent.

\section{Prevalence and Incidence}

Within the registry we calculated the age- and sexspecific prevalence of the skin diseases seen during a 5 -year period (2002-2006), as well as the incidence (all new cases) during the same period.

\section{Use of Health Care}

Questionnaires were sent to all registered patients aged 18 years or older who had commonly encountered skin diseases during the 12 months preceding the study. The questionnaire was usually not administered near the time of a visit to the family physician when the skin disease was presumably more active.

Health care use was measured by the number of contacts (visits, telephone calls for prescriptions, or contact for referrals) with the family physician for skin diseases in the previous year. Additionally, we assessed the number of contacts with other specialists and complementary or alternative medicine practitioners in the previous year.

Disease severity was assessed with a validated 9 item disease severity scale using the Impact of Skin Disease on Daily Life (ISDL), a health instrument that measures the degree to which 9 parts of the body (face, haired head, neck, hands, arms, torso, legs, feet, and genitals/anus) were affected by the disease. Response categories were on a 4 -point Likert scale ranging from "not" (1) to "totally" (4). ${ }^{20,21}$ A total score (range, 9-36) for the affected area of the body was calculated by summing the scores of the 9 items.
Physical symptoms of itching, pain, and fatigue were assessed with separate visual analogue scales (VAS) that measured the mean level of itching, pain, and fatigue during the past 4 weeks $(0=$ no itching/pain/fatigue $; 10=$ worst itching/pain/fatigue ever experienced). ${ }^{20,21}$

Disease-related quality of life was measured with the Dermatological Life Quality Index. ${ }^{22}$ Higher scores indicate a lower disease-related quality of life.

Disease duration was measured as the self-reported time since initial diagnosis in years. Groups were compared using 2-tailed Student's $t$ tests or Pearson's $\chi^{2}$.

\section{RESULTS \\ Prevalence and Incidence}

Skin diseases accounted for $12.4 \%$ of all diseases seen by family physicians in the CMR. By calculating the amount of skin diseases as a percentage of all diseases instead of the percentage of all patients, it is possible to gain a more precise insight into the frequency with which physicians encounter a disease. Table 1 shows the age- and sex-specific prevalence and incidence of each skin disease.

\section{Use of Medical Care for Skin Diseases}

Of the 857 questionnaires sent, 583 (68.0\%) were returned, and 501 were suitable for analysis. The mean age of these patients was 49.7 years (SD 17.1 years; range, $18.5-97.6$ years), $60.9 \%$ were female, and $7.4 \%$, $60.9 \%$, and $31.7 \%$ had a primary, secondary, and tertiary level of education, representing on average 7,12 , and 17 years of formal education, respectively. There was no difference by sex between the responders and nonresponders, but the responders were significantly younger $(t=3.9 ; P<.01)$. Patients with the following diagnoses returned questionnaires: 41 patients with acne vulgaris, 97 with atopic dermatitis, 27 with contact dermatitis, 11 with corns, 67 with dermatitis, 11 with diseases of sebaceous glands and sweat glands, 115 with psoriasis, 72 with seborrheic dermatitis, and 29 with seborrheic keratosis. There were fewer than 10 respondents with each of the following diagnoses: diseases of the nail, sebaceous cyst, benign neoplasm of the skin, chronic ulcer, pruritus, diseases of the hair, and the different forms of skin carcinoma. The mean duration of skin disease was 16.7 years (SD 15.5 years; range, 0.1-67.1 years).

Of the 501 patients who returned the questionnaire, $83.4 \%$ reported having contacted a family physician for their skin disease in the previous 12 months $(62.1 \%$ for visits, with a mean of 2.8 office visits; $46.3 \%$ for prescriptions, with a mean of 3.1 telephone calls; and $9.4 \%$ for referral to other specialists, with a mean 
of 1.4 contacts). Seventeen percent of the patients had visited a specialist on average 3.7 times (91.3\% visited a dermatologist). In addition, $5.2 \%$ had visited an alternative health care practitioner (on average 8.1 times).

Most patients contacted only their family physician $(\mathrm{n}=326,65.1 \%)$. Eight patients (1.6\%) visited only a specialist, and 3 patients $(0.6 \%)$ visited only an alternative health care practitioner. Sixty-eight (13.6\%) visited their family physician and a specialist, and $14(2.8 \%)$ visited their family physician and an alternative health care practitioner. In addition, $9(1.8 \%)$ patients visited their family physician, a specialist, and an alternative health practitioner, and 73 (14.6\%) did not contact a health care practitioner at all during a 12 -month period.

Table 2 compares patients who consulted a health care practitioner with those who did not. Patients who visited their family physician, another specialist, or an alternative health care practitioner reported a significantly higher disease severity, more severe itching, and a lower disease-related quality of life.

\section{DISCUSSION}

In accordance with earlier studies, ${ }^{3,4}$ skin diseases accounted for $12.4 \%$ of all diseases seen by the participating family physicians of the CMR. As expected, we found a high prevalence of, for example, psoriasis and atopic dermatitis. The CMR used standard age ranges and diagnostic categories that enabled comparison with earlier population-based data on skin disease prevalence in the Netherlands., ${ }^{3,24}$ These descriptive data indicated a possible increase in the prevalence of atopic dermatitis, seborrheic dermatitis, psoriasis, diseases of the hair, and seborrheic keratosis.

Regarding the use of medical care, our results indicated that more than $80 \%$ of all patients had contacted their family physician for their skin disease during the previous year. Moreover, $65 \%$ were treated only by their family physician during this year. Patients with more extensive disease, more itching, and a low disease-related quality of life made the most use of medical services. These findings are in line with findings for other chronic diseases. For example, Stein et $\mathrm{al}^{23}$ reported that patients with a chronic disease accompanied by severe psychosocial impairments made more frequent use of medical care.

Some limitations of the study should be kept in mind. Several subgroups of patients with specific skin diseases were relatively small, which made it impossible to examine severity, quality of life, and medical care use for specific skin diseases individually. Even so, our data suggest that the results about health care use did not differ greatly by diagnosis. Future research is needed to study the health care use of patients with specific skin diseases. Although the CMR uses generally accepted categories for skin disease that are compatible with the ICHPPC, the definition of dermatitis as a heterogeneous group of skin diseases that emerge as skin damage in reaction to a toxin may have influenced the high prevalence for this category. Finally, several variables, for example, disease duration and the number of visits to different health care practitioners, were assessed through self-report, and we cannot exclude a possible recall bias in these measurements.

Because patients with a more severe skin disease and a lower quality of life made the most frequent use of health care, paying particular attention to patients' physical symptoms and psychosocial impairments might have beneficial consequences for dermatological treatment by increasing satisfaction with treatment and patient compliance with dermatological interventions. ${ }^{25,26}$ More research is needed, however, to provide insight into the determinants of health care use and the effectiveness of current health care facilities in treating specific skin diseases.

To read or post commentaries in response to this article, see it online at http://www.annfammed.org/cgi/content/full/6/4/349.

Key words: Family practice, skin diseases, prevalence, healthcare

Submitted July 23, 2007; submitted, revised, December 13, 2007; accepted January 13, 2008.

Funding support: This study was partly supported by a grant from the Dutch Skin Foundation (Stichting Nationaal Huidfonds).

Acknowledgments: We would like to thank all family physicians of the CMR for their contribution to this study: J. C. Bakx, J. E. H. Gelpke, H. A. H. M. Lagro, A. L. M. Lagro-Janssen, H. J. Schers, A. M. Serrarens, C. P. M. Verhoeff, E. H. van de Lisdonk, W. J. H. M. van den Bosch, M. E.

T. C. van den Muijsenbergh, and H. M. A. van Ewijk - van der Wielen.

\section{References}

1. Wolkenstein P, Grob JJ, Bastuji Garin S, Ruszczynski S, Roujeau JC, Revuz J. French people and skin diseases: results of a survey using a representative sample. Arch Dermatol. 2003;139(12):1614-1619.

2. Lowell BA, Froelich CW, Federman DG, Kirsner RS. Dermatology in primary care: Prevalence and patient disposition. J Am Acad Dermatol. 2001;45(2):250-255.

3. van der Linden MW, Westert GP, de Bakker DH, Schellevis FG. Tweede nationale studie naar ziekten en verrichtingen in de huisartspraktijk. Klachten een aandoeningen in de bevolking en in de huisartspraktijk. [Second national study on morbidity and interventions in general practice. Complaints and morbidity in the general population and in general practice]. Utrecht/ Bilthoven: NIVEL/ RIVM; 2004.

4. McCormick A, Fleming D, Charlton J. Morbidity Statistics From General Practice. London: HMSO; 1995.

5. Rea JN, Newhouse ML, Halil T. Skin disease in Lambeth. A community study of prevalence and use of medical care. Br J Prev Soc Med. 1976;30(2):107-114.

6. Julian CG. Dermatology in general practice. Br J Dermatol. 1999; 141(3):518-520. 
Table 1. Skin Disease Incidence and Prevalence, 2002-2006, per 1,000 Patient-Years, by Age and Sex

\begin{tabular}{|c|c|c|c|c|c|c|c|c|c|}
\hline Skin Disease & Total & $\begin{array}{l}\text { Male } \\
\text { Total }\end{array}$ & $\begin{array}{c}\text { Female } \\
\text { Total }\end{array}$ & $\begin{array}{l}\text { Male } \\
0-4 \text { y }\end{array}$ & $\begin{array}{c}\text { Female } \\
0-4 \text { y }\end{array}$ & $\begin{array}{l}\text { Male } \\
5-14 \text { y }\end{array}$ & $\begin{array}{c}\text { Female } \\
5-14 \text { y }\end{array}$ & $\begin{array}{c}\text { Male } \\
15-24 \text { y }\end{array}$ & $\begin{array}{l}\text { Female } \\
15-24 \text { y }\end{array}$ \\
\hline \multicolumn{10}{|l|}{ Acne vulgaris } \\
\hline Incidence & 3.2 & 2.4 & 4.1 & 0.4 & 0.4 & 5.6 & 6.6 & 13.3 & 17.3 \\
\hline Prevalence & 9.6 & 5.4 & 13.7 & 0.4 & 0.4 & 7.2 & 8.6 & 35.0 & 66.9 \\
\hline \multicolumn{10}{|l|}{ Atopic dermatitis } \\
\hline Incidence & 6.1 & 6.5 & 5.7 & 56.4 & 40.4 & 7.4 & 6.2 & 2.5 & 8.4 \\
\hline Prevalence & 24.8 & 23.8 & 25.7 & 108.9 & 77.8 & 49.9 & 35.0 & 18.7 & 40.6 \\
\hline \multicolumn{10}{|l|}{ Benign neoplasm } \\
\hline Incidence & 17.5 & 14.0 & 20.8 & 1.2 & 1.7 & 2.5 & 4.4 & 7.9 & 16.1 \\
\hline Prevalence & 17.6 & 14.0 & 21.0 & 1.2 & 1.7 & 2.5 & 4.4 & 7.9 & 16.1 \\
\hline \multicolumn{10}{|l|}{ Chronic ulcer } \\
\hline Incidence & 2.1 & 1.7 & 2.5 & 0.0 & 0.0 & 0.0 & 0.0 & 0.0 & 0.0 \\
\hline Prevalence & 2.5 & 2.2 & 2.8 & 0.0 & 0.0 & 0.0 & 0.0 & 0.0 & 0.0 \\
\hline \multicolumn{10}{|c|}{ Contact dermatitis } \\
\hline Incidence & 2.5 & 1.5 & 3.5 & 0.4 & 0.8 & 1.1 & 1.3 & 2.2 & 7.1 \\
\hline Prevalence & 4.0 & 2.2 & 5.8 & 0.4 & 0.8 & 1.1 & 1.5 & 3.2 & 8.7 \\
\hline \multicolumn{10}{|l|}{ Corns } \\
\hline Incidence & 3.9 & 3.4 & 4.4 & 0.4 & 0.0 & 0.4 & 0.7 & 2.2 & 2.2 \\
\hline Prevalence & 4.0 & 3.4 & 4.5 & 0.4 & 0.0 & 0.4 & 0.7 & 2.2 & 2.2 \\
\hline \multicolumn{10}{|l|}{ Dermatitis } \\
\hline Incidence & 53.9 & 44.0 & 63.4 & 62.7 & 61.0 & 31.2 & 41.0 & 30.2 & 65.3 \\
\hline Prevalence & 64.7 & 53.4 & 75.3 & 64.3 & 61.4 & 32.6 & 43.2 & 31.5 & 75.5 \\
\hline \multicolumn{10}{|c|}{ Diseases of the hair } \\
\hline Incidence & 1.5 & 0.8 & 2.1 & 0.4 & 0.0 & 0.7 & 1.3 & 0.6 & 2.2 \\
\hline Prevalence & 2.5 & 1.4 & 3.7 & 0.4 & 0.0 & 0.9 & 1.3 & 0.6 & 2.2 \\
\hline \multicolumn{10}{|c|}{ Diseases of the nails } \\
\hline Incidence & 6.8 & 6.0 & 7.5 & 2.4 & 3.4 & 4.7 & 9.3 & 13.3 & 8.7 \\
\hline Prevalence & 6.8 & 6.1 & 7.5 & 2.4 & 3.4 & 4.7 & 9.3 & 13.3 & 8.7 \\
\hline \multicolumn{10}{|c|}{ Diseases of sebaceous glands and sweat glands } \\
\hline Incidence & 1.8 & 1.5 & 2.1 & 1.2 & 0.4 & 0.4 & 2.6 & 2.5 & 4.3 \\
\hline Prevalence & 1.9 & 1.6 & 2.1 & 1.2 & 0.4 & 0.4 & 2.6 & 3.2 & 4.3 \\
\hline \multicolumn{10}{|l|}{ Melanoma } \\
\hline Incidence & 0.2 & 0.2 & 0.3 & 0.0 & 0.0 & 0.0 & 0.0 & 0.0 & 0.0 \\
\hline Prevalence & 1.7 & 1.0 & 2.4 & 0.0 & 0.0 & 0.0 & 0.0 & 0.0 & 0.0 \\
\hline \multicolumn{10}{|l|}{ Pruritus } \\
\hline Incidence & 2.1 & 1.7 & 2.4 & 0.0 & 0.0 & 1.1 & 0.9 & 0.3 & 0.9 \\
\hline Prevalence & 2.2 & 19 & 2.5 & 0.0 & 0.0 & 1.1 & 0.9 & 0.3 & 1.2 \\
\hline \multicolumn{10}{|l|}{ Psoriasis } \\
\hline Incidence & 1.5 & 1.3 & 1.6 & 0.0 & 0.4 & 0.4 & 0.4 & 1.9 & 0.9 \\
\hline Prevalence & 15.9 & 15.5 & 16.4 & 0.0 & 0.4 & 0.9 & 0.7 & 3.8 & 7.7 \\
\hline \multicolumn{10}{|l|}{ Sebaceous cyst } \\
\hline Incidence & 10.8 & 11.2 & 10.4 & 0.4 & 0.4 & 2.5 & 0.9 & 6.7 & 9.3 \\
\hline Prevalence & 10.8 & 11.2 & 10.4 & 0.4 & 0.4 & 2.5 & 0.9 & 6.7 & 9.3 \\
\hline \multicolumn{10}{|c|}{ Seborrheic dermatitis } \\
\hline Incidence & 5.8 & 5.0 & 6.5 & 3.6 & 7.6 & 3.8 & 2.4 & 3.5 & 5.6 \\
\hline Prevalence & 12.9 & 12.8 & 13.0 & 3.6 & 7.6 & 5.4 & 4.0 & 7.0 & 9.0 \\
\hline \multicolumn{10}{|c|}{ Seborrheic keratosis (wart seborrheic) } \\
\hline Incidence & 7.2 & 6.2 & 8.1 & 0.0 & 0.0 & 0.2 & 0.0 & 0.3 & 0.3 \\
\hline Prevalence & 7.2 & 6.3 & 8.1 & 0.0 & 0.0 & 0.2 & 0.0 & 0.3 & 0.3 \\
\hline \multicolumn{10}{|c|}{ Squamous cell carcinoma } \\
\hline Incidence & 0.4 & 0.5 & 0.3 & 0.0 & 0.0 & 0.0 & 0.0 & 0.0 & 0.3 \\
\hline Prevalence & 0.6 & 0.8 & 0.5 & 0.0 & 0.0 & 0.0 & 0.0 & 0.0 & 1.5 \\
\hline
\end{tabular}

Note: Use of patient-years is necessary in long-term follow-up research because not every patient under study can be observed for the same period (because of death for example). Total number of patient-years in the registry is the sum of the observation period for all observed individuals. In this case, each month within the 5 -year period a patient could be observed counts for $1 / 12$ patient year in the total number of patient years in the network. 


\begin{tabular}{|c|c|c|c|c|c|c|c|}
\hline $\begin{array}{c}\text { Male } \\
25-44 \text { y }\end{array}$ & $\begin{array}{c}\text { Female } \\
25-44 \text { y }\end{array}$ & $\begin{array}{c}\text { Male } \\
45-64 \text { y }\end{array}$ & $\begin{array}{l}\text { Female } \\
45-64 \text { y }\end{array}$ & $\begin{array}{c}\text { Male } \\
65-74 \text { y }\end{array}$ & $\begin{array}{l}\text { Female } \\
65-74 \text { y }\end{array}$ & $\begin{array}{c}\text { Male } \\
\geq 75 \mathrm{y}\end{array}$ & $\begin{array}{l}\text { Female } \\
\geq 75 \mathrm{y}\end{array}$ \\
\hline 0.9 & 4.9 & 0.0 & 0.0 & 0.0 & 0.4 & 1.5 & 0.0 \\
\hline 3.0 & 18.8 & 0.2 & 1.7 & 0.0 & 0.4 & 1.5 & 0.0 \\
\hline 2.0 & 2.7 & 0.9 & 1.7 & 0.4 & 1.1 & 0.7 & 0.4 \\
\hline 11.9 & 22.8 & 7.6 & 11.0 & 11.3 & 18.2 & 10.4 & 11.3 \\
\hline 18.4 & 25.5 & 19.3 & 32.1 & 17.9 & 23.4 & 14.2 & 11.3 \\
\hline 18.4 & 25.5 & 19.3 & 32.4 & 17.9 & 24.4 & 14.2 & 11.3 \\
\hline 0.5 & 0.3 & 1.5 & 1.0 & 5.0 & 3.6 & 18.7 & 27.9 \\
\hline 0.6 & 0.3 & 1.8 & 1.0 & 5.8 & 3.6 & 27.6 & 32.7 \\
\hline 1.8 & 4.3 & 1.2 & 4.0 & 0.8 & 2.5 & 3.7 & 1.3 \\
\hline 2.3 & 7.0 & 2.4 & 7.7 & 2.9 & 3.6 & 3.7 & 4.4 \\
\hline 3.9 & 4.0 & 4.1 & 5.5 & 5.0 & 8.4 & 10.4 & 13.1 \\
\hline 3.9 & 4.2 & 4.1 & 5.5 & 5.0 & 8.4 & 10.4 & 13.1 \\
\hline 35.0 & 59.3 & 45.2 & 66.5 & 67.1 & 82.9 & 100.7 & 92.0 \\
\hline 42.1 & 67.0 & 57.6 & 84.5 & 89.6 & 106.5 & 147.7 & 119.9 \\
\hline 1.1 & 3.3 & 0.9 & 2.3 & 0.0 & 0.7 & 0.7 & 0.9 \\
\hline 2.0 & 4.1 & 1.8 & 3.9 & 0.4 & 7.6 & 0.7 & 6.5 \\
\hline 6.6 & 7.9 & 4.8 & 6.0 & 5.0 & 8.0 & 5.2 & 10.5 \\
\hline 6.7 & 7.9 & 5.0 & 6.0 & 5.0 & 8.0 & 5.2 & 10.5 \\
\hline 2.1 & 2.5 & 1.2 & 1.6 & 1.7 & 0.7 & 1.4 & 0.9 \\
\hline 2.2 & 2.5 & 1.3 & 1.6 & 1.7 & 0.7 & 1.4 & 0.9 \\
\hline 0.1 & 0.3 & 0.2 & 0.6 & 0.4 & 0.7 & 0.7 & 0.4 \\
\hline 0.5 & 2.2 & 1.7 & 4.8 & 2.1 & 2.5 & 6.0 & 5.2 \\
\hline 0.6 & 2.0 & 2.4 & 3.1 & 3.8 & 2.2 & 9.7 & 10.0 \\
\hline 0.6 & 2.2 & 3.0 & 3.1 & 4.6 & 2.2 & 9.7 & 10.0 \\
\hline 1.5 & 1.9 & 1.4 & 2.2 & 1.7 & 1.5 & 2.2 & 3.1 \\
\hline 13.0 & 12.8 & 21.0 & 20.0 & 46.2 & 39.3 & 46.3 & 51.9 \\
\hline 15.1 & 12.4 & 14.9 & 13.8 & 11.3 & 15.6 & 17.2 & 11.8 \\
\hline 15.1 & 12.4 & 15.0 & 13.8 & 11.3 & 15.6 & 17.2 & 11.8 \\
\hline 3.8 & 6.4 & 6.3 & 6.9 & 9.2 & 6.2 & 9.0 & 13.5 \\
\hline 8.9 & 11.7 & 17.4 & 16.7 & 20.8 & 14.9 & 53.7 & 31.8 \\
\hline 2.9 & 3.7 & 12.2 & 16.3 & 14.6 & 19.3 & 21.6 & 18.7 \\
\hline 2.9 & 3.7 & 12.2 & 16.3 & 15.0 & 19.3 & 21.6 & 18.7 \\
\hline 0.0 & 0.0 & 0.2 & 0.3 & 2.9 & 0.4 & 4.5 & 1.7 \\
\hline 0.0 & 0.0 & 0.4 & 0.5 & 5.4 & 0.7 & 6.0 & 3.5 \\
\hline
\end{tabular}


Table 2. Comparison of Patients Who Visited a Health Care Provider With Those Who Did Not (Student's $t$ Test)

\begin{tabular}{|c|c|c|c|c|c|c|c|c|c|}
\hline \multirow[b]{2}{*}{ Characteristics } & \multicolumn{3}{|c|}{ Contact Family Physician } & \multicolumn{3}{|c|}{ Contact Specialist } & \multicolumn{3}{|c|}{$\begin{array}{l}\text { Contact Alternative } \\
\text { Health Practitioner }\end{array}$} \\
\hline & $\begin{array}{c}\text { Yes } \\
(n=417 \\
\text { Mean (SD) }\end{array}$ & $\begin{array}{c}\text { No } \\
(n=84) \\
\text { Mean (SD) }\end{array}$ & $\begin{array}{c}P \\
\text { Value }\end{array}$ & $\begin{array}{c}\text { Yes } \\
(n=85) \\
\text { Mean (SD) }\end{array}$ & $\begin{array}{c}\text { No } \\
(n=416) \\
\text { Mean (SD) }\end{array}$ & $\begin{array}{c}P \\
\text { Value }\end{array}$ & $\begin{array}{c}\text { Yes } \\
(n=26) \\
\text { Mean (SD) }\end{array}$ & $\begin{array}{c}\text { No } \\
(n=475) \\
\text { Mean (SD) }\end{array}$ & $\begin{array}{c}P \\
\text { Value }\end{array}$ \\
\hline Age & $49.7(17.5)$ & $49.7(15.1)$ & NS & $50.1(19.2)$ & $49.6(16.7)$ & NS & $40.3(13.3)$ & $50.2(17.1)$ & $<.01$ \\
\hline Sex & $0.6(0.5)$ & $0.6(0.5)$ & NS & $0.7(0.5)$ & $0.6(0.5)$ & NS & $0.8(0.4)$ & $0.6(0.5)$ & NS \\
\hline Educational level & $4.3(2.0)$ & $4.2(2.0)$ & NS & $4.2(2.0)$ & $4.3(2.0)$ & NS & $4.8(2.0)$ & $4.3(2.0)$ & NS \\
\hline Disease severity ${ }^{b}$ & $12.5(2.8)$ & $11.2(2.4)$ & $<.01$ & $13.3(3.3)$ & $12.1(2.6)$ & $<.01$ & $14.0(3.1)$ & $12.2(2.7)$ & $<.01$ \\
\hline $\begin{array}{l}\text { Disease duration, } \\
\text { years }\end{array}$ & $16.7(15.6)$ & $17.7(14.7)$ & NS & $15.6(17.6)$ & $17.1(15.0)$ & NS & $21.3(14.4)$ & $16.1(15.5)$ & NS \\
\hline Itche & $3.4(2.7)$ & $2.0(2.3)$ & $<.01$ & $3.9(3.0)$ & $3.0(2.6)$ & $<.05$ & $4.8(2.8)$ & $3.0(2.6)$ & $<.01$ \\
\hline Painc & $1.6(2.0)$ & $1.2(1.7)$ & $<.05$ & $1.9(2.2)$ & $1.5(1.9)$ & NS & $2.7(2.7)$ & $1.5(1.9)$ & $<.05$ \\
\hline Fatigue $^{c}$ & $3.2(2.8)$ & $2.5(2.6)$ & $<.05$ & $3.3(3.0)$ & $3.1(2.8)$ & NS & $4.3(2.8)$ & $3.0(2.8)$ & $<.05$ \\
\hline DLQI ${ }^{d}$ & $4.3(4.9)$ & $2.4(3.8)$ & $<.01$ & $5.6(5.6)$ & $3.7(4.5)$ & $<.01$ & $10.3(7.3)$ & $3.7(4.3)$ & $<.01$ \\
\hline
\end{tabular}

DLQI = Dermatological Life Quality Index; ISDL = Impact of Skin Disease on Daily Life.

${ }^{\text {a } 0}=$ male, 1 = female, compared through Pearson's $\chi^{2}$.

${ }^{\mathrm{b}}$ As measured by ISDL, range, 9-36.

c Assessed with visual analogue scales: $0=$ no itch/pain/fatigue; 10 = worst itch/pain/fatigue ever experienced

${ }^{d}$ Higher scores indicate lower disease-related quality of life.

7. Dennis LK. Analysis of the melanoma epidemic, both apparent and real: data from the 1973 through 1994 surveillance, epidemiology, and end results program registry. Arch Dermatol. 1999;135(3):275-280

8. Gelfand JM, Weinstein R, Porter SB, Neimann AL, Berlin JA, Margolis DJ. Prevalence and treatment of psoriasis in the United kingdom a population-based study. Arch Dermatol. 2005;141(12):1537-1541.

9. Grize L, Gassner M, Wuthrich B, et al. Trends in prevalence of asthma, allergic rhinitis and atopic dermatitis in 5-7-year old Swiss children from 1992 to 2001. Allergy. 2006;61(5):556-562.

10. de Vries E, van de Poll Franse LV, Louwman WJ, de Gruijl FR, Coebergh JW. Predictions of skin cancer incidence in the Netherlands up to 2015. Br J Dermatol. 2005;152(3):481-488.

11. Schultz Larsen F, Diepgen T, Svensson A. The occurrence of atopic dermatitis in north Europe: an international questionnaire study. J Am Acad Dermatol. 1996;34(5 Pt 1):760-764.

12. Hanstock TL, O'Mahony JF. Treatment seeking in young women with acne. Dermatol Psychosom. 2003;4:194-199.

13. van den Bosch WJ. Forty years family-based morbidity data in general practice. Scand J Prim Health Care Suppl. 1993;2:31-32.

14. van Weel C. Validating long term morbidity recording. J Epidemiol Community Health. 1995;49(Suppl 1):29-32.

15. van Weel C, Smith H, Beasley JW. Family practice research networks. Experiences from 3 countries. J Fam Pract. 2000;49(10):938-943.

16. van Weel C. Longitudinal research and data collection in primary care. Ann Fam Med. 2005;3(Suppl 1):S46-S51.

17. Hodgkin K. Towards Earlier Diagnosis in Primary Care. Edingburgh: Churchill Livingstone; 1978.
18. College of General Practitioners. A classification of disease. J R Coll Gen Pract. 1959;2:140-159.

19. Classification Committee of WONCA. ICHPPC-2-Defined. Oxford: Oxford University Press; 1984.

20. Evers AWM, Duller $P$, van de Kerkhof PCM, et al. The impact of chronic skin diseases on daily life (ISDL): a generic and dermatology-specific health instrument. Br J Dermatol. 2008;158:101-108.

21. Evers AW, Lu Y, Duller $P$, van der Valk PG, Kraaimaat FW, van de Kerkhof PC. Common burden of chronic skin diseases? Contributors to psychological distress in adults with psoriasis and atopic dermatitis. Br J Dermatol. 2005;152(6):1275-1281.

22. Finlay AY, Khan GK. Dermatology Life Quality Index (DLQI)-a simple practical measure for routine clinical use. Clin Exp Dermatol. 1994;19(3):210-216.

23. Stein MB, Cox BJ, Afifi TO, Belik SL, Sareen J. Does co-morbid depressive illness magnify the impact of chronic physical illness? A population-based perspective. Psychol Med. 2006;36(5):587-596.

24. van de Lisdonk EH, van den Bosch WJHM, Lagro-Janssen ALM. Ziekten in de Huisartspraktijk [Diseases in Family Medicine]. Maarsen: Elsevier; 2003.

25. Renzi C, Abeni D, Picardi A, et al. Factors associated with patient satisfaction with care among dermatological outpatients. Br J Dermatol. 2001;145(4):617-623.

26. Renzi C, Picardi A, Abeni D, et al. Association of dissatisfaction with care and psychiatric morbidity with poor treatment compliance. Arch Dermatol. 2002;138(3):337-342. 